S.V. Syrotyuk

\title{
Electronic Properties of Orthorhombic InI and TII Crystals Taking into Account the Quasiparticle Corrections and Spin-Orbit Interaction
}

\author{
Lviv Polytechnic National University, Lviv, Ukraine, svsnpe@ gmail.com
}

\begin{abstract}
The electronic properties of InI and TII crystals of an orthorhombic structure with a space group Cmcm are studied. Calculations of electron properties are performed in the basis of projector augmented waves by means of ABINIT program. Total and partial densities of electronic states are calculated. Electron energy spectra are found with the exchange-correlation functional GGA, without and taking into account the spin-orbital interaction. It was found that the band gap of the InI, obtained without spin-orbital interaction, is less than the experimental value by $38 \%$, and by $42 \%$, taking into account the latter. For the TII crystal, the corresponding values are $27 \%$ and $39 \%$. The band gap found from the quasiparticle equation in the GW approximation exhibits an excellent agreement with the experimental values for both crystals.
\end{abstract}

Keywords: semiconductor, spin-orbit coupling, Green's function, energy spectrum, DOS.

Received 5 October 2020; Accepted 15 December 2020.

\section{Introduction}

InI and TII crystals crystallize in an orthorhombic structure, the spatial group of which is $\mathrm{Cmcm}$ (63), and the unit cell contains 8 atoms [1]. These are semiconductors with interband gaps of 2.01 and $2.84 \mathrm{eV}$, respectively. The work [1] is devoted to the theoretical and experimental study of structural, electronic and optical properties of solid solutions $\operatorname{In}_{x} T l_{1-x} I$. The practical application of these solutions is associated with the possibility of operating with a material whose band gap varies from $2.01 \mathrm{eV}$ to $2.84 \mathrm{eV}$.

Attempts to calculate the electronic energy spectrum of InI and TII crystals have a long history. In particular, in [2] it was found that crystals have indirect band gaps. In [3], a direct band gap was found at the point $\Gamma$ of the Brillouin zone. In works [4-7] the direct band gap was found, but not located at the point $\Gamma$. In a work [8], a band gap was found at the Q point in the Brillouin zone.

Summarizing up a brief review of the calculations of the electronic energy band structure for InI and TII, we note that in a work [1] the nature of the interband gap is clearly established on the basis of the measured structural parameters of the unit cell.

Two circumstances prompted the implementation of the study outlined in this article. The first one is connected with underestimated values of the band gap $\varepsilon_{g}$. The interband gaps of solid solutions calculated in [1] are much smaller than the experimental ones. For example, for the concentration $\mathrm{x}=1$, i.e. in the $\mathrm{InI}$ crystal, the value of $\varepsilon_{g}=1.34 \mathrm{eV}$ was found, while the experiment gives the value of $2.01 \mathrm{eV}$. The second circumstance is the lack of data in the literature on the influence of spin-orbit interaction on the formation of the electronic energy spectrum of both crystals.

Therefore, the aim of this study is to obtain the electronic energy bands in InI and TII crystals without and with the spin-orbit interaction, as well as more accurate values of the band gaps. And now let's focus on the solving these problems.

\section{Theory}

The electronic energy band spectrum of the crystal 


\section{S.V. Syrotyuk}

was obtained using the ABINIT program [9] based on the basis of projectior augmented waves (PAW) [10]. The PAW basis functions have been generated using the AtomPAW code [11]. The exchange-correlation potential was selected in the form of GGA-PBE [12] obtained from the functional of the exchange-correlation energy.

In the PAW method, the true all electron function $\psi_{\alpha}$ is obtained by the action of the operator $\tau$ on some smooth function $\tilde{\psi}_{\alpha}$ :

$$
\psi_{\alpha}=\tau \tilde{\psi}_{\alpha}, \tau=1+\sum_{a} \sum_{\alpha}\left(\left|\varphi_{\alpha}^{a}>-\right| \tilde{\varphi}_{\alpha}^{a}>\right)<\tilde{p}_{\alpha}^{a} \mid,
$$

where an operator $\tau$ is built on the all electronic $\varphi_{\alpha}$, pseudo-wave $\tilde{\varphi}_{\alpha}$ and projector functions $\tilde{p}_{\alpha}$, respectively. We search the electronic energy band spectrum and wave functions from the Schrödinger equation [10],

$$
H\left|\psi_{\alpha \mathbf{k}}>=E_{\alpha \mathbf{k}}\right| \psi_{\alpha \mathbf{k}}>.
$$

The Hamiltonian operator is represented as follows:

$$
H=-\frac{1}{2} \nabla^{2}+V_{e x t}(\mathbf{r})+V_{C}(\rho(\mathbf{r}))+V_{x c}(\rho(\mathbf{r})),
$$

where $-\frac{1}{2} \nabla^{2}$ is the kinetic energy operator, $V_{\text {ext }}$ the pseudo-potential of the ion, and the potentials $V_{C}$ and $V_{x c}$ correspond to the Coulomb and exchange-correlation interactions, respectively. Index $=\{\mathbf{k} ; \mathrm{n}, 1, \mathrm{~m}\}$ covers the quantum numbers $\mathrm{n}, \mathrm{l}, \mathrm{m}$, and $\mathbf{k}$ is a quasi-wave vector in the first Brillouin zone. Substituting (1) in equation (2) we obtain the transformed pseudo-wave equation:

$$
\tau^{+} H \tau\left|\tilde{\psi}_{\alpha \mathbf{k}}>=\tau^{+} \tau\right| \tilde{\psi}_{\alpha \mathbf{k}}>E_{\alpha \mathbf{k}} .
$$

The energy spectra, found from the quations (2) and (4) are identical.

Effective Hamiltonian without the spin-orbit interaction is represented in the form [10],

$$
\tilde{H}=\tau^{+} H \tau=-\nabla^{2} / 2+v_{e f f}+\sum_{i, j}\left|\tilde{p}_{i}>D_{i j}<\tilde{p}_{j}\right|,
$$

where $v_{\text {eff }}$ and $D_{i j}$ are the energy parameters depending on the crystal electronic density, Coulomb and exchangecorrelation potentials. In the PAW method, the spin-orbit interaction is taken into account by modifying only the last term in formula (5) [9]:

$$
\tilde{H}=-\nabla^{2} / 2+v_{e f f}+\sum_{i, j}\left|\tilde{p}_{i}>\left(D_{i j}+D_{i j}^{s o}\right)<\tilde{p}_{j}\right| .
$$

Calculations performed on the basis of equations (1) - (6) allowed us to obtain the densities of electronic states and electronic energy band spectra. The latter were found without the spin-orbit interaction, as well as taking it into account. Calculations performed on the basis of equations (1) - (6) allowed obtaining the densities of electronic states and electronic energy spectra. It is clear that equations (1) - (6) are defined in the framework of the theory of the total electron density functional, i.e. in the GGA-PBE. In this approach, we obtained electronic energy band spectra, which are characterized by values of interband gaps that are much smaller than those measured.

More precise values of the band gap were found using the Green's function approach in the $\mathrm{GW}$ approximation [9] based on the norm-concerving pseudopotentials [13] and the screend exchangecorrelation hybrid functional HSE06 [14]. Recently we have completed a testing of this approach for the calculation of electronic energy band spectra in dielectrics [15] and semiconductors [16]. In both cases, a good comparison of theoretical and experimental values of the band gap of the crystals was found.

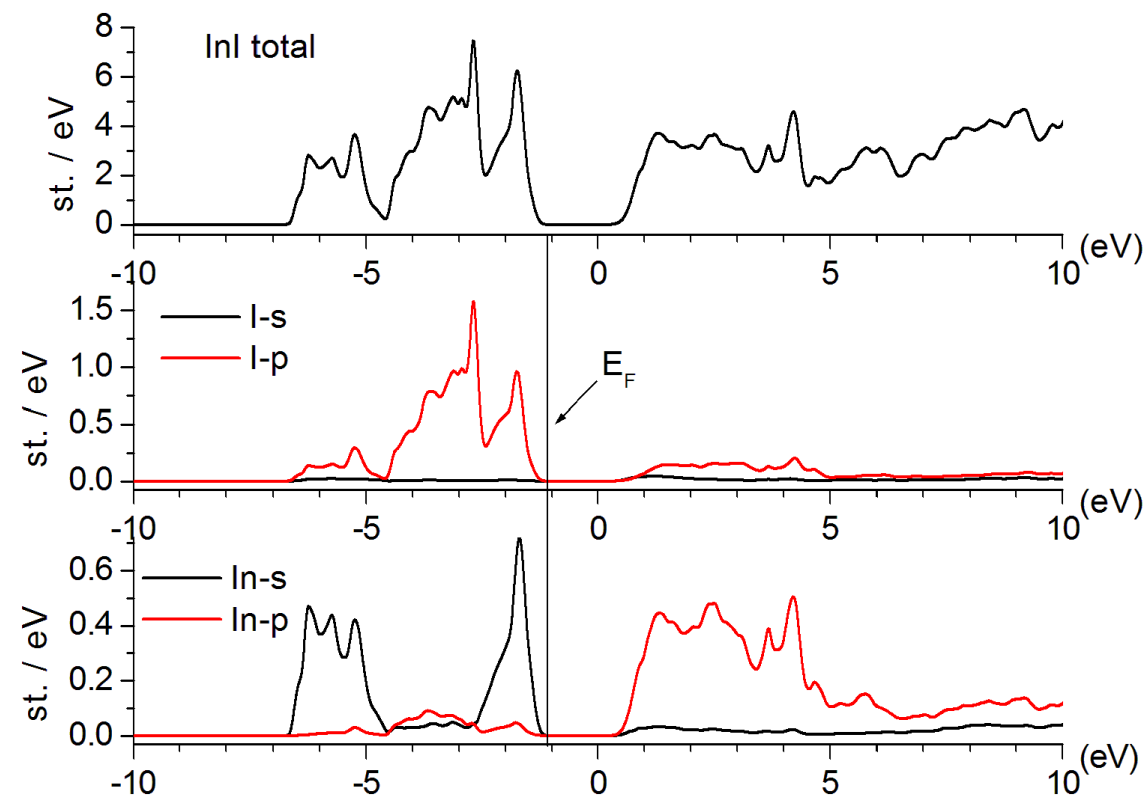

Fig. 1. Partial and total density of electronic states in the InI crystal. 


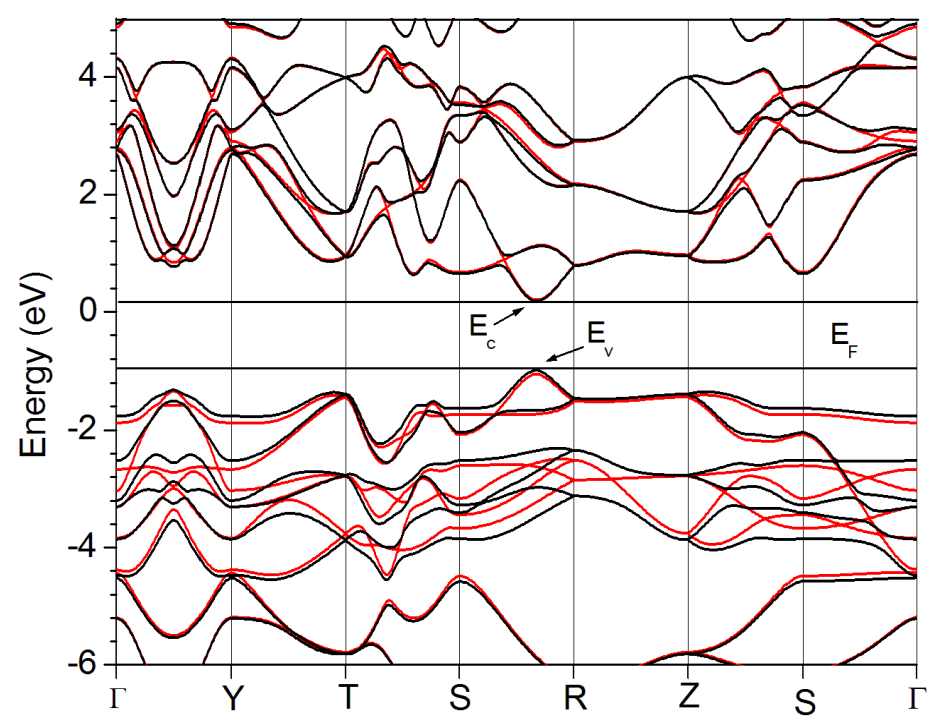

Fig. 2. Electronic energy spectrum of the InI crystal, obtained without and with the spin-orbit interaction (red and black curves, respectively).

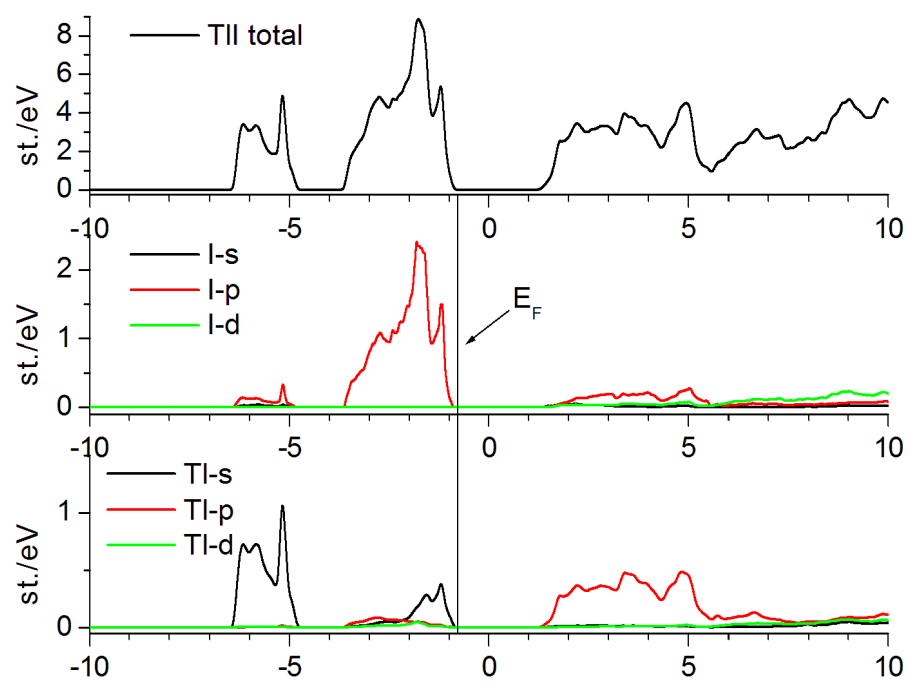

Fig. 3. Partial and total density of electronic states in the TII crystal.

\section{Analysis and interpretation of results}

Figure 1 shows the densities of the electronic states of the InI crystal obtained in the PAW-GGA formalism. Note that the upper part of the valence band consists of p-states of iodine and s-states of indium. Obviously, they are highly hybridized. And in the conduction band is dominated by p-states of indium.

Figure 2 represents the electronic energy dispersion curves in an InI crystal. The red curves were obtained without the spin-orbit interaction, and the black ones were obtained taking into account the latter. Note that the spin-orbit interaction leads to a marked splitting of the branches of the degenerate spectrum in the valence band. In the conduction band, this effect is negligible. The interband gap is direct and is located on the line $\mathrm{S}-\mathrm{R}$, namely at the point $(0.5,0.5,0.32)$ of the first Brillouin zone. The spin-orbit interaction caused the ceiling of the valence band in InI to move up by $0.067 \mathrm{eV}$, and the bottom of the conduction band down by $0.019 \mathrm{eV}$. Thus, the band gap is decreased by $0.086 \mathrm{eV}$. The band gap of the InI crystal is $1.252 \mathrm{eV}$ and $1.166 \mathrm{eV}$ without and taking into account the spin-orbit interaction. These values of the band gap are smaller than the experimentally measured by 38 and 42 percent, respectively.

Figure 3 shows the densities of the electronic states in the TII crystal. Note that the upper part of the valence band is formed by p-states of iodine and s-states of thallium. The deeper part of the valence band is also filled with s-states of the thallium.

Spectral curves shown in Fig. 4, reveal larger 


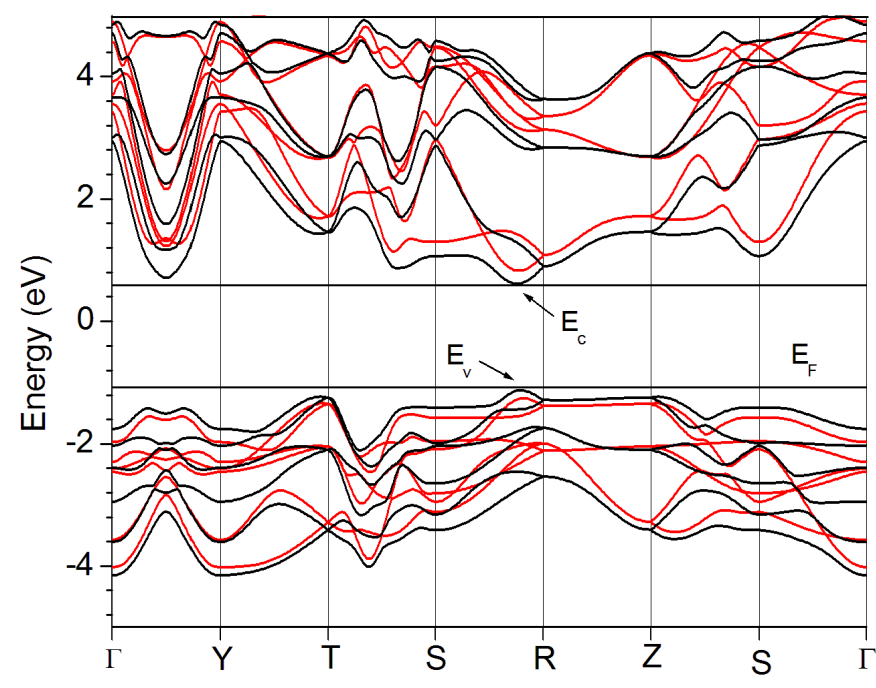

Fig. 4. Electronic energy spectrum of the TII crystal, obtained without and with the spin-orbit interaction (red and black curves, respectively).

splittings caused by the to spin-orbit interaction, both in the valence band and in the conduction one. Thus, the top of the valence and the bottom of the conduction band is shifted by $0.133 \mathrm{eV}$ upwards and by $0.209 \mathrm{eV}$ downwards, respectively. That is, the band gap is decreased by $0.342 \mathrm{eV}$. The band gap without the spinorbit interaction is of $2.082 \mathrm{eV}$, and taking into account the latter of $1.740 \mathrm{eV}$, respectively. These values of the band gap are smaller than the experimentally measured by 27 and 39 percent, respectively. Therefore, the theoretical values of the band gap, calculated for InI and TI crystals, are much smaller than those found experimentally. This underestimation of the band gaps is typical for the semiconductors and dielectrics. Here we correct this error within the Green's function approach [9], implemented in the ABINIT code in the form of the GW approximation.

Finally, we give here more accurate values of the band gaps found in the GW approximation. For InI, the $\mathrm{GW}$ band gap is $2.076 \mathrm{eV}$, and after subtracting the spinorbit narrowing of $0.086 \mathrm{eV}$, we obtain final value, $\varepsilon_{g}=$ $1.99 \mathrm{eV}$, which is perfectly comparable to the experimental one of $2.01 \mathrm{eV}$ [1]. For TII the GW band gap equals to $3.152 \mathrm{eV}$, and the spin-orbit narrowing is $0.342 \mathrm{eV}$, so the final band gap value $\varepsilon_{g}=2.81 \mathrm{eV}$, which is well compared with the experimentally measured value of $2.84 \mathrm{eV}$ [1].

\section{Conclusion}

The electronic energy band spectra of InI and TII crystals are calculated taking into account the spin-orbit interaction with the exchange-correlation potential in the GGA-PBE formalism. The band gaps of both crystals were less than the experimental value. More precise values of the band gaps were obtained using the Green's function in the GW approximation. The band gaps, found here, were corrected by the value of spin-orbit narrowing energy, which led to a good comparison with the experiment. The results, obtained here, can be used to calculate the electronic structure of regular InTII solid solutions. The splitting of the energies in the degenerate zones, shown in Figs. 2, 4, may be a significant limiting factor reducing the accuracy of the calculation of the optical constants InI and TII, as well as solid solutions InTII.

Syrotyuk S.V. - Ph.D., Associate Professor, Associate Professor of the Department of Semiconductor Electronics.

[1] A.I. Kashuba, M. Piasecki, O.V. Bovgyra, V.Yo. Stadnyk, P. Demchenko, A. Fedorchuk, A.V. Franiv, B. Andriyevsky, Acta Phys. Polon. 133, 68 (2018) (https://doi.org/10.12693/APhysPolA.133.68).

[2] M.I. Kolinko, J. Phys. Condens. Matter 6, 183 (1994) (https://doi.org/10.1063/1.1353711).

[3] Z. Wei, X. Zhao-Peng, W. Hai-Yan, C. Fei-Hong, H. Chang, Acta Phys. Sin. 62, 243101 (2013) (https://doi.org/10.7498/aps.62.243101).

[4] M.I. Kolinko, R.Y. Bibikov, Z. Phys. B Cond.Mat. 95, 167 (1994).

[5] M.I. Kolinko, Phys. Rev. B 55, 4007 (1997) (https://doi.org/10.1103/PhysRevB.55.4007).

[6] M.I. Kolinko, A.H. Nevidomskyy, J. Phys. Stud. 4, 437 (2000).

[7] M.I. Kolinko, O.V. Bovgyra, Ukr. J. Phys. 46, 707 (2001). 
[8] X. Zhao-Peng, W. Yong-Zhen, Z. Wei, W. Qian, W. Guo-Qing, Acta Phys. Sin. 63, 147102 (2014) (doi: 10.7498/aps.63.147102).

[9] X. Gonze et al., Comput. Phys. Comm. 205,106 (2016) (https://doi.org/10.1016/j.cpc.2016.04.003).

[10] P.E. Blöchl, Phys. Rev. B 50, 17953 (1994) (https://doi.org/10.1103/PhysRevB.50.17953).

[11] N.A.W. Holzwarth, A.R. Tackett, G.E. Matthews, Comput. Phys. Commun. 135, 329 (2001) (https://doi.org/10.1016/S0010-4655(00)00244-7).

[12] J.P. Perdew, K. Burke, M. Ernzerhof, Phys. Rev. Letters $77, \quad 3865 \quad$ (1996) (https://doi.org/10.1103/PhysRevLett. 77.3865).

[13] M. Ernzerhof, G.E. Scuseria, J. Chem. Phys. 110, 5029 (1999) (https://doi.org/10.1063/1.478401).

[14] D.R. Hamann, Phys. Rev. B 88, 085117 (2013) (https://doi.org/10.1103/PhysRevB.88.085117).

[15] S.V. Syrotyuk, Ya.M. Chornodolskyy, A.S. Voloshinovskii, Yu.V. Klysko, J. Phys. Stud. 23, 2704 (2019) (https://doi.org/10.30970/jps.23.2704).

[16] S.V. Syrotyuk, O.P. Malyk, J. Nano- Electron. Phys. 11, $06018 \quad$ (2019) (https://doi.org/10.21272/jnep.11(6).06018).

\title{
С.В. Сиротюк
}

\section{Електронні властивості орторомбічних кристалів InI та TII з урахуванням квазічастинкових поправок та спін-орбітальної взаємодії}

\author{
Наиіональний університет "Львівська політехніка", Львів, Україна, svsnре@ gтаіl.coт
}

\begin{abstract}
Вивчаються електронні властивості кристалів InI й TII орторомбічної структури 3 просторовою групою $\mathrm{Cmcm}$. Розрахунки електроних властивостей виконані в базисі проекційно приєднаних хвиль за допомогою програми ABINIT. Розраховані повні й парціальні густини електронних станів. Електронні енергетичні спектри знайдені за допомогою обмінно-кореляційного функціонала GGA-PBE без i 3 урахуванням спін-орбітальної взаємодії. Виявлено, що ширина забороненої зони InI, отримана без спінорбітальної взаємодії, менша за екпериментальне значення на 38 \%, і на $42 \%$ - з урахуванням останньої. Для кристала TII відповідні значення дорівнюють $27 \%$ і $39 \%$. Міжзонні щілини, знайдені 3 квазічастинкового рівняння в наближенні $\mathrm{GW}$, виявляють добре зіставлення 3 експериментальними значеннями для обидвох кристалів.

Ключові слова: напівпровідник, спін-орбітальна взаємодія, функція Гріна, енергетичний спектр,
\end{abstract} густина електронних станів. 